\title{
EL PAPEL DEL PRINCIPIO DEL PLACER Y DEL PRINCIPIO DE LA REALIDAD EN \\ LA FORMACIÓN DE LA SUBJETIVIDAD RACIONAL
}

\author{
THE ROLE OF THE PLEASURE PRINCIPLE \\ AND THE REALITY PRINCIPLE IN \\ THE CONSTRUCTION OF RATIONAL \\ SUBJECTIVITY
}

\author{
Miguel Ángel Bueno Espinosa* \\ Universidad Complutense de Madrid
}

\begin{abstract}
Resumen: Uno de los procedimientos localizados por Freud desde sus más tempranos trabajos fue la complementación del principio del placer por el principio de la realidad, cuya incorporación supone la marca del nacimiento de una conciencia activa en el sujeto capaz de regir deliberadamente los procesos de la subjetividad y atender a la realidad externa a él. Tal significativa transformación de nuestro aparato anímico, sin embargo, no fue detalladamente estudiada por el iniciador del psicoanálisis. Teniendo en cuenta la gran importancia de este momento biográfico para el surgimiento de la subjetividad racional, resulta crucial comprobar en detalle el significado de tal transformación, para poder establecer una base adecuada acerca de nuestro conocimiento de esa capacidad racional del ser humano.
\end{abstract}

\footnotetext{
*Miguel Ángel Bueno Espinosa: C/ Virgen de Lourdes, 28, 12-4, 28027, Madrid; mbueno@ ucm.es, Personal investigador predoctoral del Departamento de Filosofía Teorética de la Facultad de Filosofía de la Universidad Complutense de Madrid
} 
Palabras Clave: Ello, principio del placer, principio de la realidad, pulsión, resistencia, $y o$.

AвstRACT: One of the procedures located by Freud starting in his earliest works is to complement the pleasure principle with the principle of reality, the incorporation of which signifies the birth of an active consciousness in the subject, capable of deliberately ruling the processes of subjectivity and paying attention to external reality. This meaningful transformation of our mental system was not, however, studied in detail by the inventor of psychoanalysis. Taking into account the great importance of this biographical milestone for the emergence of rational subjectivity, it is crucial to check in detail the meaning of this transformation, in order to establish a proper basis for our knowledge of this rational ability.

KeYwords: Drive, ego, id, pleasure principle, principle of reality, resistance.

\section{Introducción}

Es indudable que el psicoanálisis, como doctrina especulativa de la subjetividad y como práctica terapéutica, posee una importancia determinante en el siglo $\mathrm{XX}$, no sólo dentro de la historia de la psicología, sino también en la historia general del pensamiento. Ya en La interpretación de los sueños ${ }^{l}$ aparece una sección, considerada por Freud como "psicología especulativa", dedicada a describir la naturaleza, las características, las instancias y la dinámica del aparato anímico, tal y como éste podía ser conocido a partir de la labor práctica de recopilación de datos en la clínica, y de interpretación y terapia.

Uno de los procesos anímicos que el psicoanálisis describe dentro de su dimensión especulativa, pero en el que no realiza una incursión especialmente detallada, es el proceso según el cual lo que Freud denominó principio del placer es complementado en la infancia por el principio de la realidad. Este momento supone, dentro de la biografía de cada individuo, una modificación de la subjetividad de carácter trascendental que funciona como condición de posibilidad de todo el desarrollo intelectual del que el individuo es capaz en su madurez. Ahora bien, teniendo en cuenta la importancia de dicho proceso, sorprende el poco

1 (FREUD, S., 1942-1973, Bd. II-III) [existe traducción al español: FREUD, S., 1993]. En lo sucesivo se citará esta edición de las obras completas de FREUD como GW, indicando el tomo $(\mathrm{Bd})$ en el que la obra en cuestión se encuentra, y a continuación se indicará la correspondiente información relativa a la traducción al español de dicha obra. 
material aportado tanto por Freud como por el resto de investigadores psicoanalíticos a la hora de entender con mayor detalle los acontecimientos psíquicos reunidos en esa complementación.

Con el estudio que vamos a llevar a cabo aquí pretendemos en parte rellenar ese vacío teórico. Consideramos imprescindible comprender adecuadamente lo que acontece en ese momento determinante de nuestra biografía, de modo que dirigiremos nuestra atención a ese proceso, y buscaremos apuntar una explicación teórica capaz de dar justa cuenta de él. Para ello llevaremos a cabo un breve pero suficiente acercamiento teórico a la doctrina básica del psicoanálisis, con el objetivo de definir el marco teórico que funciona de horizonte en las explicaciones psicoanalíticas de ese proceso, así como de aportar las nociones y conceptos que nos servirán de base para su estudio.

\section{Conciencia e inconsciente}

La teoría psicoanalítica acerca del aparato anímico del ser humano encuentra su base en la afirmación de que los flujos subjetivos se definen principalmente por su carácter pulsional: la subjetividad es, esencialmente, pura tensión desiderativa, pulsiones de deseo. El sujeto, en su núcleo, es pura "yección» al exterior bajo la forma de una pulsión desiderativa. Todas las demás transformaciones y complicaciones que experimente esta subjetividad fundamental en la maduración biográfica de los sujetos encontrarán su explicación dinámica en este carácter intencionalmente desiderativo de los flujos psíquicos².

2 Este concepto de pulsión (Trieb, traducido por Luis López-Ballesteros y de Torres como «instinto») no está libre de grandes problemas y ambigüedades. El concepto mismo posee su propia historia interna, aunque la marca general que siempre mantuvo la pulsión, como noción fundamental de la concepción dinámica de la psique que caracteriza al psicoanálisis, fue la de elemento psicológico básico o simple: "si consideramos la vida anímica desde el punto de vista biológico, se nos muestra el «instinto» [Trieb] como un concepto límite entre lo anímico y lo somático, como un representante psíquico de los estímulos procedentes del interior del cuerpo que arriban al alma y como una magnitud de la exigencia de trabajo impuesta a lo anímico a consecuencia de su conexión con lo somático." (FREUD, S., 19421973, GW, Bd. X, St. 214) ["Los instintos y sus destinos”, en: FREUD, S., 2004, pág. 146]. Posteriormente esta explicación dinámica vino a completarse con la introducción del concepto de libido, el cual representa la carga o tensión que incorpora cada una de las pulsiones, que las pone en movimiento, y que, debido a ese movimiento, le aporta una cualidad u otra: "El concepto de la libido (...) es una unidad dinámica. (...) La libido que nos sirve de concepto fundamental, no sólo no es concreta ni conocida, sino que es una verdadera $X$ desconocida, una mera hipótesis, un simil o una unidad de medida. (...) Libido no debe ser otra cosa sino un 
Para llevar a cabo nuestro proyecto, partiremos en primer lugar de lo que podemos denominar la hipótesis topográfica del psicoanálisis, que divide la subjetividad en dos regiones claramente diferenciadas por su concepto pero confundidas y mezcladas fenoménicamente: la región de la conciencia, a la que tenemos un acceso directo por reflexión y observación, y la región de lo inconsciente, cuya existencia es siempre presupuesta a modo de hipótesis explicativa por el psicoanálisis en la medida en que todo acceso a ella es necesaria y metódicamente indirecto a través de sus efectos conscientes.

Por definición, la conciencia es el órgano psíquico de nuestro aparato anímico encargado de recoger información de la realidad externa, de atender y regular los estímulos recibidos por parte de elementos exteriores a nuestra subjetividad, y, en último término, opera como el intermediario entre nuestro mundo interior y el mundo externo y extrańo a nosotros. La conciencia reúne igualmente gran parte de los procesos intelectuales que llevamos a cabo, desde el presupuesto de que todos esos procesos intelectuales poseen, en su base, la función de adaptación al medio y de supervivencia que los originaron evolutivamente.

Lo inconsciente, en cambio, reúne bajo sí todos los fenómenos psíquicos de los que no somos directamente conscientes, y cuya existencia conocemos única y exclusivamente a partir de la observación y del análisis de ciertos procesos conscientes para los que necesitamos presuponer, como causa, la existencia de esos procesos inconscientes ${ }^{3}$.

Esta hipótesis topográfica se completa con la hipótesis institucional que Freud introdujo con la publicación de El yo y el ello, según la cual dentro de la psique

nombre para aquella energía que se manifiesta en el proceso de la vida, y que nosotros percibimos como un afán o un deseo. (...) Observamos en la multiplicidad de los fenómenos naturales la voluntad, la libido, bajo diferentes aplicaciones y formas." (JUNG, C.G., 1972, págs. 46 y 63-64). Para evitar los conflictos interpretativos que puede ocasionar el uso del término "libido", dada la carga semántica sexual del concepto español, hablaremos aquí simplemente de flujos pulsionales más o menos cargados, de un fluir libre u obstaculizado o estancado.

3 "Hemos hallado recursos técnicos que permiten colmar las lagunas de nuestros fenómenos conscientes. (...) Por ese camino elucidamos una serie de procesos que, en sí mismos, son "incognoscibles"; los insertamos en la serie de los que no son conscientes, y si afirmamos, por ejemplo, la intervención de un determinado recuerdo inconsciente, sólo queremos decir que ha sucedido algo absolutamente inconceptuable para nosotros, pero algo que, si hubiese llegado a nuestra consciencia, sólo hubiese podido ser así, y no de otro modo.” (FREUD, S., 1942-1973, GW, Bd. XVII, St. 127) [FREUD, S., Compendio del psicoanálisis, en: FREUD, S., 1979, pág. 162]. 
humana, y repartidas entre las dos regiones topográficas ya descritas, existen tres entidades principales, en torno a las que gira toda la actividad subjetiva: el ello, el yo y el super-yo. Para los propósitos teóricos que nos estamos planteando aquí podemos permitirnos prescindir momentáneamente de la tercera entidad, y centrarnos única y exclusivamente en el ello y el yo.

El yo está constituido internamente por todos y cada uno de los procesos dinámicos que podemos comprobar en la conciencia de un sujeto. De esta manera, hablar de los procesos de control y de redireccionamiento ejercidos por el yo como controlador de la conciencia implica en realidad hablar de las propias tendencias mecánicas de la dinámica de los fenómenos conscientes ${ }^{4}$. Todos los procesos subjetivos y mecanismos de control que el psicoanálisis encuentra en el yo no suponen entonces un elemento externo a los mismos procesos subjetivos sobre los que se aplica, sino que, por el contrario, constituyen un producto inmanente a ellos mismos, un resultado derivado de su propia dinámica ${ }^{5}$. Nuestra psique está constituida por una única naturaleza psíquica originaria, las pulsiones de lo inconsciente, que, en su despliegue y desarrollo, devienen conscientes por su choque con la realidad, y que en ese enfrentamiento con algo otro-de-sí vienen a imponerse a sí mismas todas esas actitudes de control y redireccionamiento como un resultado mecánico de su propia dinámica y de la incorporación de esas resistencias a su propio flujo.

Por su parte, el ello reúne el núcleo primitivo de pulsiones que constituye el origen de la subjetividad ${ }^{6}$. A diferencia del yo, el ello no se puede considerar en sentido estricto como una entidad con una actitud propia. Lo inconsciente, por definición, es caótico, se mueve por puro impulso y se despliega sin un proyecto

4 "Suponemos en todo individuo una organización coherente de sus procesos psíquicos, a la que consideramos como su yo. Este yo integra la conciencia, la cual domina el acceso a la motilidad, esto es, la descarga de las excitaciones en el mundo exterior, siendo aquélla la instancia psíquica que finaliza todos sus procesos parciales. (...) Del yo parten también las represiones por medio de las cuales han de quedar excluidas, no sólo de la conciencia, sino también de las demás formas de eficiencia y actividad, determinadas tendencias anímicas." (FREUD, S., 1942-1973, GW, Bd. XIII, St. 243) [FREUD, S., 2009, pág. 11].

5 "La importancia funcional del yo reside en el hecho de regir normalmente los accesos a la motilidad. Podemos, pues, compararlo, en su relación con el ello, al jinete que rige y refrena la fuerza de su cabalgadura." (Ibidem, St. 253) [Ibidem, pág. 19].

6 El psicoanálisis plantea la hipótesis de que en la psique humana debe poder encontrarse la misma historia genética que en la filogénesis, de manera que la envoltura de la conciencia madura esconda en su interior elementos que supongan restos biológicos de etapas psicológicas evolutivas anteriores. (Cfr. FREUD, S., 1942-1973, GW, Bd. XIV, \$1 [FREUD, S., $2004, \$ 1]$. 
concreto distinto a su único y verdadero objetivo: la satisfacción irreflexiva de las pulsiones inconscientes. Incluso en este punto originario su movimiento es mecánico y por azar, puramente pulsional. Por este motivo, el ello, entidad central de lo inconsciente, es el nombre común que utilizamos para referirnos al conjunto de los fenómenos inconscientes en los que reconocemos el patrón común de comportamiento de su carácter inconsciente.

El carácter de deseo que define a las pulsiones del ello consiste en un impulso del organismo dirigido a la obtención de un bien interno o externo que satisface una situación inestable o perentoria de éste: el sujeto experimenta una sensación de displacer respecto a un fenómeno fisiológico o psíquico, y esa misma sensación negativa es la que despliega los mecanismos necesarios que ponen en juego pautas de conducta dirigidas a la eliminación de esa situación de inestabilidad y al retorno al estado "normal" de estabilidad homeostática en el que el sujeto puede permanecer en reposo.

\section{Los destinos del deseo: satisfacción primaria y satisfacción secundaria}

De este modo el psicoanálisis concibe el deseo, siguiendo la tradición clásica, en los términos de una carencia, y siempre bajo los criterios generales de los principios dinámicos y económicos de la subjetividad. Así, sostiene que la situación originaria y permanente del organismo y de la psique, a la que tienden por sí mismos según una suerte de principio de inercia natural, es una situación de estabilidad homeostática ${ }^{7}$.

En esta situación aparecen distorsiones de este equilibrio producidas inicialmente por condiciones fisiológicas menesterosas, que generan una situación inestable en esa homeostasis, una carencia, que se traduce en términos económicos en una sobrecarga tensional; en términos dinámicos, la obstaculización del fluir libre de una necesidad hacia el elemento que la satisface detiene el fluido y genera un retrotraimiento circular del mismo ante su imposibilidad de discurrir

7 Esta estabilidad homeostática presenta una semejanza respecto al estado inanimado de la materia que precede evolutivamente al surgimiento de la vida. "Un instinto sería, pues, una tendencia propia de lo orgánico vivo a la reconstrucción de un estado anterior, que lo animado tuvo que abandonar bajo el influjo de fuerzas exteriores, perturbadoras (...), o, si se quiere, la manifestación de la inercia en la vida orgánica." (FREUD, S., 1942-1973, GW, Bd. XIII, St. 38) [FREUD, S., 2005, pág. 116]. 
según su curso propio, lo que produce sobrecargas tensionales del libre flujo subjetivo correspondiente a esas funciones fisiológicas. Esas distorsiones presentan, por ello mismo, ya determinadas características propias de las cualidades del segmento de flujo en el que se ha producido, que definen la carencia como siendo una carencia de una categoría u otra. No es lo mismo, en efecto, carecer de alimento que carecer de cobijo. Las pulsiones correspondientes al segmento desestabilizado adquirirán mecánicamente las cualidades propias de la carencia en cuestión, de manera que, aunque todavía no posean un objeto de deseo claramente determinado, al menos su pulsionalidad o intencionalidad tensional ya se encuentra categorialmente determinada por la misma tensión fisiológica que la genera, proyectando esa determinación categorial todo un universo de objetos de deseo que podrían venir a satisfacerlo en caso de cumplir ciertas notas.

A partir de aquí, cuando el sujeto experimenta por primera vez ese deseo, y en el despliegue conductual consecuente encuentra por azar un objeto adecuado para satisfacerlo, esa victoria de la conducta inconsciente y arbitrariamente desplegada marca un camino al deseo para posteriores ocasiones, de manera que ese deseo queda fijado a ese objeto de deseo concreto y a partir de ese momento irá principalmente dirigido a él para ser satisfecho. Posteriormente, la repetición de la victoria conductual genera la costumbre en el flujo y le delimita cada vez más el camino directo hacia su satisfacción.

Por lo tanto, hablar de un objeto de deseo propio de un deseo concreto supone simplemente hacer referencia a aquel objeto o tipos de objetos que, en el despliegue mecánico del flujo pulsional, ha conseguido vincular la conducta del sujeto con la consecución de ese bien, estableciendo un hábito conductual, un circuito mecánico cerrado ${ }^{8}$. A partir de ese momento, todo establecimiento

8 La idea de un objeto de deseo propio de un deseo concreto resulta harto problemática, tal y como subrayaron insistentemente Deleuze y Guattari. Freud se introduce en esta problemática al considerar el deseo como una carencia de algo, como si el deseo, como tal, fuera siempre deseo de una entidad determinada. Deleuze y Guattari, en su El Anti Edipo, anularon este carácter predefinido del deseo con su teoría de las máquinas deseantes, estableciendo el carácter puramente pulsional del ello y mostrando los devenires mecánicos que los flujos de deseo experimentan en su fijación a ciertos objetos. "Desde el momento en que colocamos al deseo al lado de la adquisición, obtenemos una concepción idealista (dialéctica, nihilista) del deseo que, en primer lugar, lo determina como carencia. (...) En efecto, si el deseo es carencia del objeto real, su propia realidad forma parte de una «esencia de la carencia» que produce el objeto fantasmático. (...) En el nivel más bajo de la interpretación, esto significa que el objeto real del que el deseo carece remite por su cuenta a una producción natural o social extrínseca, mientras que el deseo produce intrínsecamente un imaginario que dobla a la realidad, 
futuro de un circuito conductual determinado supondrá siempre una reconfiguración de un circuito anterior, o, en el caso del primer condicionamiento, una primera figuración de un flujo totalmente libre.

Partiendo de este hecho, Freud distingue entre dos tipos de satisfacciones de deseos, la satisfacción primaria y la secundaria o derivada. La primaria es aquélla en la que el deseo efectúa su propio camino hacia el objeto de deseo correspondiente, sin encontrar ningún tipo de obstáculo y sin sufrir ninguna clase de mediación consciente. La satisfacción secundaria, en cambio, se caracteriza por la existencia de redireccionamientos efectuados en el flujo del deseo, de tal modo que éste ya no se dirige de manera directa o inmediata hacia el objeto de deseo que tiene fijado, sino que sólo se dirige hacia él a través de modificaciones internas del propio deseo o del objeto correspondiente? ${ }^{9}$ Por algún motivo el curso normal de un deseo concreto no es permitido o no puede desenvolverse hasta el final, de manera que ese deseo queda a partir de ese momento insatisfecho, generando el proceso de elaboración del deseo que caracteriza las satisfacciones secundarias.

La existencia de esta distinción entre las satisfacciones primarias y las secundarias resulta decisiva en la historia de la subjetividad humana, ya que es la necesidad de elaborar los flujos de deseo primarios a partir de la imposibilidad de una satisfacción directa la que empujará evolutivamente a la subjetividad humana a desarrollar los mecanismos conductuales e intelectuales que caracterizan la conciencia activa y que permiten su distanciamiento cualitativo respecto del resto de seres animales en lo que concierne a capacidad lógica y racional de deliberación ${ }^{10}$.

como si hubiese «un objeto sońado detrás de cada objeto real». (...) Si el deseo produce, produce lo real. Si el deseo es productor, sólo puede serlo en realidad, y de realidad." (DELEUZE, G. Y GUATTARI, F., 2010, págs. 32-33).

9 "Las demandas instintuales, apartadas de su satisfacción directa, se ven obligadas a adoptar nuevas vías que llevan a satisfacciones sustitutivas, y en el curso de esos rodeos pueden ser desexualizadas, aflojándose su vinculación con sus fines instintivos originales." (FREUD, S., 1942-1973, GW, Bd. XVII, Stn. 131-132 [FREUD, S., Compendio del psicoanálisis, en: FREUD, S., 1979, pág. 167].

10 "En lugar de la represión que excluía de toda carga psíquica una parte de las representaciones emergentes, como susceptibles de engendrar displacer, surgió el discernimiento, instancia propuesta a decidir si una representación determinada es verdadera o falsa, esto es, si se halla o no de acuerdo con la realidad, y que lo decide por medio de su comparación con las huellas mnémicas de la realidad.” (FREUD, S., 1942-1973, GW, Bd. VIII, St. 233) [FREUD, S., "Los dos principios del suceder psíquico", en: FREUD, S., 2009, pág. 141]. 
Lo que caracteriza entonces esta satisfacción secundaria es la existencia de una elaboración sobre el curso original del flujo subjetivo en la que a éste se le imponen ciertos nódulos internos o puntos de intersección y redistribución que intercalan su despliegue y lo redirigen de cierta manera. En todos y cada uno de los procesos de satisfacción secundaria de deseos existe una suerte de puntos mediáticos o intermediarios que funcionan a modo de nódulos redistributivos del flujo original de deseo, modificando su dirección o su cualidad, y consiguiendo que el deseo, una vez haya pasado por ellos, no pueda ser considerado exactamente el mismo que se originó en un primer momento.

Esos nódulos intermedios de reconfiguración deben su existencia a las exigencias de la realidad, la cual, no permitiendo, por el motivo que sea, la satisfacción directa de un deseo concreto, impone a ese flujo la necesidad de una reconfiguración. Si tenemos en cuenta este hecho, nuestra atención ya no se dirigirá simplemente hacia el flujo de deseo reconfigurado, ni hacia las imposiciones y elaboraciones que el yo lleva a cabo sobre él, sino que se dirigirá hacia el mismo momento de choque o enfrentamiento entre la pulsión y la realidad, hacia el punto de frontera en el que el impulso directo e inmediato de la pulsión encuentra una resistencia a su flujo libre.

\section{Del principio del placer al principio de la realidad}

Lo inconsciente originario está regido por el reinado despótico del principio del placer, en la medida en que todas las pulsiones inconscientes originarias buscan siempre su satisfacción como una manera de obtener placer y de evitar el displacer. En este estado primario, la subjetividad del infante está caracterizada por lo que Freud denomina "sentimiento oceánico»" ${ }^{11}$, esto es, por un estado absoluto, omniabarcante e indiferenciado de la subjetividad, en la que los flujos se encuentran tan confundidos entre sí que resulta completamente imposible establecer una clara diferenciación entre ellos. La actividad psíquica y motora del infante es un puro caos pragmático de espasmos prácticos y movimientos aleatorios en busca de una satisfacción imposible de definir dentro del magma subjetivo indiferenciado.

11 "Nuestro actual sentido yoico no es, por consiguiente, más que el residuo atrofiado de un sentimiento más amplio, aun de envergadura universal, que correspondía a una comunicación más íntima entre el yo y el mundo circundante. (...) De esta suerte, los contenidos ideativos que le corresponden serían precisamente los de infinitud y de comunicación con el Todo.” (FREUD, S., 1942-1973, GW, Bd. XIV, St. 425) [FREUD, S., 2004, págs. 11-12]. 
Las satisfacciones que el infante experimenta presentan para él, por ello, un carácter completamente inmanente a su subjetividad: el objeto que satisface un deseo no es considerado todavía como una entidad externa al propio cuerpo o a la propia subjetividad, su origen externo queda oculto en el todo oceánico de lo inconsciente. Los flujos pulsionales incorporan de manera confusa y omniabarcante el origen o fuente de la inestabilidad, la tendencia a su satisfacción y el objeto que la aporta.

En filosofía conocemos muy bien cuál es ese estado psíquico que Freud denomina sentimiento oceánico: lo definimos como la forma de la conciencia idealista absoluta o radical, aquélla en la que la realidad externa se encuentra absorbida e indiferenciada respecto a los elementos internos a la subjetividad. Su opuesto es la forma de la conciencia realista, la cual considera ciertas representaciones inmanentes a la conciencia como la señal o el síntoma de la afección por parte de un elemento externo a ella, la realidad. Así, mientras que la totalidad de la conciencia realista está, por así decirlo, dividida en dos secciones, según los contenidos de nuestras vivencias sean considerados como inmanentes a nuestra conciencia o como representaciones del mundo externo, la totalidad de la conciencia idealista, como ocurre con la subjetividad dominada completamente por lo inconsciente, no presenta tal distinción propio-ajeno, por lo que experimenta un estado omniabarcante e indiferenciado de vivencias psíquicas que no pueden experimentarse de manera delimitada por culpa de la confusión del flujo de la conciencia.

La ruptura de esa inmanencia absoluta o idealista vendrá producida, tal y como es nuestro objetivo mostrar, por la incorporación de la conciencia de la realidad externa, que encuentra su origen en el choque de la intencionalidad operatoria caótica con resistencias externas. Pues el carácter externo de esas resistencias no puede quedar ahogado o perdido dentro de la conciencia idealista; creando así una quiebra en la corriente misma de las vivencias y en cada vivencia particular que experimenta esa resistencia. Este hecho separa en su interior al sujeto que experimenta la resistencia del objeto externo que la produce ${ }^{12}$.

12 "Lo característico de esta sensación [resistencia] es representar a la vez dos cosas que se excluyen una fuera de la otra, el alma no percibe la solidez como si fuera una de esas modificaciones en las cuales sólo se encuentra a sí misma. (...) He aquí, por lo tanto, una sensación merced a la cual el alma sale de sí misma." (CONDILLAC, È. B., 1963, II - V, \$3, pág. 147.) 
Ocurre frecuentemente que el libre fluir de las pulsiones inconscientes, dominado por el principio del placer, encuentra en un punto determinado una frontera de choque con algo-otro que le impide continuar su camino directo e inmediato hacia su objeto fijado. Desestabilizado así continuamente por esa sobrecarga, el aparato anímico se ve forzado a abandonar su dimensión alucinatoria autoerótica y a tomar en consideración creciente la información que los sentidos aportan acerca de las circunstancias de la realidad que permiten o impiden el libre fluir de los flujos hacia su objeto de deseo. Esos sentidos habían estado activos desde el principio de la vida del infante; sin embargo, debido al carácter idealista del sentimiento oceánico que presenta el aparato anímico en este momento de su biografía, esos estímulos habían quedado ahogados en la inmanencia idealista de lo inconsciente. Lo que despierta la necesidad de atender al origen externo de esos estímulos es precisamente la reiteración de la insatisfacción de los deseos, desde la constatación en esas situaciones de choque con resistencias externas de que son las circunstancias de esa realidad extraña las que determinan la posibilidad de alcanzar o no la esperada satisfacción ${ }^{13}$.

Surge así en la superficie de la subjetividad inconsciente una capa funcionalmente determinada de fenómenos psíquicos dirigidos a prestar atención a la información aportada por el sistema perceptivo acerca de la realidad. Resulta necesaria una entidad regidora de los flujos capaz de diferenciar entre ellos, de redistribuirlos, de codificar la información que presenta cada uno, y de guiar, en general, la vida psíquica. Esa entidad, como señalamos anteriormente, es el $y o$, que instaura el reinado de la conciencia sobre lo inconsciente mediante la incorporación en su interior de las características de esas resistencias externas bajo lo que Freud denomina principio de la realidad. De manera que lo que antes se experimentaba como un obstáculo externo que impedía el libre flujo del deseo ahora se experimenta como una reconfiguración interna elaborada por el yo según las exigencias interiorizadas del principio de la realidad.

El yo consciente forma entonces parte del mismo flujo subjetivo que el ello inconsciente, pues éste es el único flujo existente en el aparato anímico. Su origen está marcado por la necesidad funcional por parte del ello de generar una herramienta capaz de atender a la realidad y a las condiciones que ésta impone

13 "La decepción ante la ausencia de la satisfacción esperada motivó luego el abandono de esta tentativa de satisfacción por medio de alucinaciones, y para sustituirla tuvo que decidirse [la actividad psíquica] a representar las circunstancias reales del mundo exterior y tender a su modificación real." (FREUD, S., 1942-1973, GW, Bd. VIII, St. 231) [FREUD, S., "Los dos principios del suceder psicológico"; en: FREUD, S., 2009, pág. 140]. 
para la satisfacción de sus deseos, gestionando de manera eficiente los procesos motrices y racionales ${ }^{14}$.

El principio de la realidad no viene, según esto, a desbancar completamente al principio del placer, completamente irrenunciable. El enfrentamiento con la realidad no supone la negación del principio del placer, sino únicamente su complicación interna, su maduración: el principio de la realidad no niega el principio del placer, sino que lo complementa con su función de realidad para perfeccionarlo allí donde su reinado indiscriminado puede llegar a suponer la destrucción del individuo por falta de discernimiento.

\section{La inmanencia/trascendencia de la resistencia: génesis del par yo/no-yo y toma de conciencia de la realidad}

Hasta aquí llega la descripción especulativa que el psicoanálisis ofrece acerca de este proceso de complementación del principio del placer por el principio de la realidad. El problema que da origen a nuestro estudio surge por el hecho de que Freud expone este proceso siempre como si se debiese a una decisión del sujeto, del propio aparato anímico; como si éste, llegado un momento, decidiese voluntariamente sustituir el control del principio del placer por la adquisición del principio de la realidad ${ }^{15}$. Sin embargo, la propia naturaleza inconsciente del aparato anímico en el momento de tomar esa supuesta decisión imposibilita tal procedimiento, pues el discernimiento, la atención a la realidad y la reconfiguración de los flujos son precisamente operaciones propias del yo que surgiría como resultado de esa decisión. De modo que resulta imposible que el yo lleve a cabo las operaciones previas que dan lugar a su propia génesis.

14 "El yo deberá discriminar entre las representaciones deseadas y las percepciones actuales, para lo que deberá pensar, o sea comparar, comprender, buscar la identidad (que lo deseado y lo percibido sean una misma cosa), pero discriminando hasta dónde sí y hasta dónde no, o en qué sentido sí o en qué sentido no, o en qué sí y en qué no, etc." (VALLS, J. L., "Aparato psíquico, patología y realidad”, Revista de Psicoanálisis (Buenos Aires), 1990, vol. 47, no 3, pág. 500). "El yo es una parte del ello modificada por la influencia del mundo exterior. (...) El yo se esfuerza en transmitir a su vez al ello dicha influencia del mundo exterior, y aspira a sustituir el principio del placer, que reina sin restricción en el ello, por el principio de la realidad. La percepción es para el yo lo que para el ello el instinto." (FREUD, S., 1942-1973, GW, Bd. XIII, Stn. 252-253) [FREUD, S., 2009, págs. 18-19].

15 En la cita que incorporamos en la nota 14 Freud usa literalmente el verbo "decidir" a la hora de exponer este proceso. 
En nuestra opinión, el principio de la realidad no surge espontáneamente en la conciencia del sujeto, como si el infante descubriese súbitamente cómo es la realidad. Por el contrario, su incorporación a la conciencia está marcada precisamente por el surgimiento progresivo de la propia conciencia activa del sujeto, a diferencia de su inconsciencia idealista pasiva, de tal manera que cuanto más consciente es el sujeto de sí mismo, más consciente es de su no-yo, y viceversa. La función de realidad es una función aprendida, en el sentido más estricto de la expresión. En este sentido, todo el proceso aparentemente simple de la complementación del reinado del principio del placer por el principio de la realidad oculta el gran salto cualitativo que supone la incorporación a la subjetividad de la noción de alteridad, de realidad externa e independiente a la propia conciencia.

Señalar este punto resulta determinante a la hora de concebir adecuadamente la historia de la formación de una subjetividad racional. Por eso, para finalizar nuestro estudio, estudiaremos con detalle las características y consecuencias de este proceso de complementación del principio del placer por el principio de la realidad. El núcleo de esta cuestión se encuentra, evidentemente, en el estudio del paso de la satisfacción primaria a la satisfacción secundaria. Ya que el surgimiento de la conciencia, y, con ella, de las capacidades racionales e intelectivas que ésta desarrollará en el futuro, está marcado por la transformación interna del aparato anímico que implica la instauración del llamado proceso secundario.

Las imposiciones y reconfiguraciones que el yo lleva a cabo sobre los flujos de deseo inconscientes, que caracterizan la satisfacción secundaria, tienen su causa en las resistencias externas que quedan interiorizadas en el principio de la realidad. Cuando el camino que discurre entre la pulsión desiderativa y el objeto que tiene fijado su curso se ve interrumpido porque alguna condición de la realidad no permite su satisfacción directa, lo que el deseo experimenta es una resistencia externa a su propia tendencia. No se trata todavía de la conciencia regidora que impide continuar por ese camino, sino de la presencia de algo-otro del deseo que impide su libre fluir, ofreciendo una resistencia que la pulsión en cuestión no puede salvar. Por ello, el deseo no puede experimentar ese obstáculo como algo propio e intrínseco al mismo flujo que es detenido, ya que de lo contrario no habría motivo para no poder salvarlo.

Y, aun así, esa resistencia sigue siendo en cierto modo inmanente al aparato anímico que se construye y despliega en ese deseo. El elemento que ejerce esa resistencia al libre fluir del deseo se presenta ante el deseo como externo a él; pero la experiencia de esa resistencia, el choque como tal, el bloqueo o el punto 
de limitación de los flujos anímicos, es completamente interno a la subjetividad que lo experimenta, pues, de lo contrario, nunca llegaría a experimentarlo. La vivencia del choque entre el deseo y el elemento externo resistente opuesto a él nunca se da fuera de la conciencia, sino dentro de ella misma, como un elemento inmanente más de la conciencia idealista. Serán justamente las características peculiares de ese elemento inmanente incapaz de ser considerado como propio las que rompan esa inmanencia subjetiva idealista y abran la conciencia a la realidad, a la conciencia de algo extraño, algo otro-de-sí.

En el lugar en el que acontece esa resistencia se genera un punto de frontera, un limite, en el que se encuentran dos fuerzas de dirección contraria. El choque de estas dos fuerzas es lo que determina el desarrollo ulterior del flujo de deseo, pues ese punto de frontera o de choque funciona en realidad como un momento de disyunción del flujo pulsional, que tendrá que desviar su dirección anterior y encontrar otros caminos, e incluso otros posibles objetos de deseo en los que conseguir su satisfacción, para poder salvar ese obstáculo que ha encontrado.

En toda frontera, en todo límite de choque, existen siempre dos entidades que se encuentran y se contraponen, no es suficiente la presencia de una sola de ellas para poder dar lugar al choque y a la consecuente generación de una frontera. Si la existencia de una frontera es tan importante en el devenir de los flujos de deseo es precisamente porque, a pesar de estar generada por una resistencia externa al flujo de deseo, implica igualmente la fuerza o empuje de ese deseo, del mismo modo que implica la fuerza o empuje de la resistencia ${ }^{16}$.

Por eso, aun teniendo en cuenta la naturaleza externa de la resistencia que genera la frontera, no puede afirmarse estrictamente que la necesidad de redirigir el flujo de deseo hacia una satisfacción secundaria sea causada única y exclusivamente por el elemento externo que impide la satisfacción primaria.

16 Una característica remarcable de las reflexiones psicoanalíticas de Deleuze es la de señalar que los flujos subjetivos de la conciencia reciben su sentido y su valor siempre en su relación con otros flujos o con los objetos de la realidad. Deleuze aprendió esta idea del pensamiento de Nietzsche y la aplicó al concepto de máquina deseante del esquizoanálisis: "Se trata de una disyunción inclusiva que realiza ella misma la síntesis derivando de un término a otro y siguiendo la distancia. No existe nada originario." (DELEUZE Y GUATTARI, 2010, pág. 83); "Eso son las máquinas deseantes: máquinas formativas, cuyos propios fallos son funcionales y cuyo funcionamiento es indiscernible de la formación; (...) donde el todo es él mismo producido al lado de las partes." (Ibidem, pág. 296.) 
Pues en esa necesidad el deseo obstaculizado juega un papel tan importante como el de la resistencia que lo obstaculiza. De no ser así resultaría absurdo hablar de una incorporación de las resistencias reales bajo la forma del principio de la realidad, ya que las resistencias reales, por definición, son siempre externas a nuestra subjetividad ${ }^{17}$.

La entidad que produce la resistencia no queda extraída del propio fenómeno psíquico o vivencia debido a su carácter de obstáculo. Lo que ocurre en las situaciones de este tipo es que ese objeto, inmanente a la propia subjetividad, nos obliga a considerarlo precisamente como ajeno a nuestro control y poder debido a la resistencia que opone a nuestro deseo, e impone la necesidad de una reelaboración de la conciencia, con el objetivo de complicar el flujo subjetivo para que pueda apoderarse de esa exterioridad que le ha sido privada por la resistencia.

En este punto es en el que juega su papel la importante quiebra del «sentimiento oceánico", que localizamos como el momento trascendental de la formación de la subjetividad activa. El punto central de nuestra argumentación queda localizado en el hecho fenomenológicamente constatable de que la resistencia, siendo inmanente a la propia conciencia, aparece como algo extraño, algo otro-de-sí, precisamente por su carácter de resistencia. En este sentido, la frontera generada por esa resistencia presenta de manera «bilógica» una inmanencia y una trascendencia.

Desde el momento en el que se genera esa frontera, podemos distinguir dentro de esa vivencia dos elementos funcionalmente distintos: el elemento interno a nuestra propia subjetividad, el deseo que fluye libremente desde el ello, y el elemento resistente, aquello otro-de-sí que detiene ese flujo desde fuera y le impide avanzar. Estos dos elementos funcionalmente diferentes crean una quiebra en la inmanencia idealista absoluta de la subjetividad, generando un punto de fuga desde el que proyectarse hacia una trascendencia que no puede ser interiorizada. La conciencia se divide en dos polos: el polo interno, aquello que podemos controlar y que reconocemos como propio, y el polo externo, aquello que se muestra como independiente y resistente a nuestro poder.

17 "La realidad es siempre construida en una dimensión fantasmática, único enlace posible del sujeto con el mundo exterior." (GURMAN, I. Y PAULUCCI, O. A., "Acerca de la transferencia, la pulsión y el lugar del analista”, Revista de Psicoanálisis (Buenos Aires), 1990, vol. 47, no 3, pág. 487.) 
La simple acumulación de experiencias de este tipo enriquecerá paulatinamente ese punto de quiebra, esa fuga interna, obligando cada vez más a los flujos de deseo a tomar en consideración los elementos externos en su busca de satisfacción. Atendiendo a esa necesidad, los despliegues desiderativos serán cada vez menos mecánicos y más intencionados, su flujo estará poco a poco cada vez más deliberadamente dirigido, con el objetivo de poder responder de un modo más económicamente satisfactorio a esas resistencias externas. Finalmente, esa atención a lo externo resistente quedará completamente establecida con la incorporación de esas resistencias en el principio de la realidad. La aparición de la conciencia y del yo son así símbolo de la quiebra de la forma idealista absoluta de la conciencia y la incorporación en la inmanencia subjetiva de una trascendencia. La conciencia activa, tal y como la conocemos desde nuestra experiencia madura, tiene por tanto un origen correlativo a la toma de conciencia de la realidad externa.

\section{Conclusión}

Podemos entonces afirmar, tal y como era nuestro objetivo mostrar, que la incorporación del principio de la realidad se revela como un momento trascendental en la historia biográfica de los seres racionales respecto a nuestra capacidad racional. Ya que gracias a la toma de conciencia de una realidad externa es como surge en nosotros una conciencia activa, capaz de actuar, de deliberar y gobernar, de pensar y decidir. 


\section{Bibliografía:}

CONDILLAC, ÈTIENNE BONNOT DE (1963), Tratado de las sensaciones, Buenos Aires, Ed. Eudeba, trad. Gregorio Weinberg.

DELEUZE, GILLES Y GUATTARI, FELIX (2010), El Anti Edipo, Madrid, Paidós, trad. Francisco Monge.

FREUD, SIGMUND (1973), Gesammelte Werke, London, Imago Publishing Co., 1942, Frankfurt am Main, S. Fischer Verlag.

- (1993), La interpretación de los sueños, Madrid, Alianza Editorial, trad. Luis LópezBallesteros y de Torres.

- (2005), Psicología de las masas, Madrid, Alianza Editorial, trad. Luis López-Ballesteros y de Torres.

- (2009), El yo y el ello, Madrid, Alianza Editorial, trad. Luis López-Ballesteros y de Torres y Ramón Rey Ardid.

- (2004), El malestar en la cultura, Madrid, Alianza Editorial, trad. Luis López-Ballesteros y de Torres y Ramón Rey Ardid.

- (1979), Esquema del psicoanálisis y otros escritos de doctrina psicoanalitica, Madrid, Alianza Editorial, trad. Luis López-Ballesteros y de Torres y Ramón Rey Ardid.

GURMAN, ISIDORO Y PAULUCCI, OSCAR ADOLFO (1990), "Acerca de la transferencia, la pulsión y el lugar del analista", Revista de Psicoanálisis (Buenos Aires), vol. 47, no 3, págs. 486-497.

VALLS, JOSÉ LUIS (1990), "Aparato psíquico, patología y realidad", Revista de Psicoanálisis (Buenos Aires), vol. 47, no 3, 498-507.

JUNG, CARL GUSTAV (1972), Teoría del psicoanálisis, Barcelona, Plaza \& Janes, trad. F. Oliver Brachfeld. 
Enviado: 23/04/2015

Aceptado: 21/05/2015

Este trabajo se encuentra bajo una licencia de Creative Commons ReconocimientoNoComercial-SinObraDerivada 4.0 